\title{
SURVEY OF CONTROL METHODS FOR DC-DC CONVERTERS
}

\author{
Martin LEŠO, Jaroslava ŽILKOVÁ, Milan BIROŠ, Peter TALIAN \\ Department of Computers and Mechatronics, Faculty of Electrical Engineering and Informatics, \\ Technical University of Košice, Letná 9, 04200 Košice, Slovak Republic, \\ E-mail: martin.leso@tuke.sk, jaroslava.zilkova@tuke.sk,milan.biros@tuke.sk, peter.talian@tuke.sk
}

\begin{abstract}
The paper presents a survey of the currently used control methods for DC-DC converters and the current state of research in this area. Determining the ideal method for output voltage control in DC-DC converters is a demanding task due to their nonlinear character, various types of connection, and ways of use. The currently prevailing control methods implemented in DC-DC converters are voltage-mode, current-mode and hysteretic control. Each of these methods comes with certain drawbacks, which is why there is intensive research going on aimed at more progressive DC-DC converter control methods that would replace or supplement the currently used types of control in order to increase the reliability and quality of DC-DC converters output voltage control. The paper includes a basic description of each of the control methods with focus on the principles of their function and on the main pluses and minuses of each method.
\end{abstract}

Keywords: dc-dc converter, control methods, fuzzy.

\section{INTRODUCTION}

Switching DC-DC converters can be considered as the most frequently used power electronics devices due to their high efficiency and flexibly adjustable output voltage. They are used in power supply to various electronic devices with emphasis on output voltage stability even with changes of input supply voltage and converter load. The following has to be taken into account in converter control method design:

- nonlinearity of circuits caused by nonlinear elements used in the converter

- circuit stability in transient states, at input voltage and converter load changes, converter stability over a wide control range

- possibility of application in higher order converters

- cost reduction of control structure implementation

- electromagnetic interference (EMI) reduction

Two of the most frequently used DC-DC converter output voltage control methods are voltage-mode and current-mode converter control, each of which comes with certain drawbacks. Setting the controller parameters for each of the methods is made so that the controller would compensate for the converter filter and the load. In the case when the load that the converter will be supplying is not known, ideal values of the controller parameters cannot be set precisely. As an alternative to voltage-mode and current-mode control, hysteretic control is used, with which it is difficult to predict controller behaviour when supplying different devices. The drawbacks of the above mentioned methods have generated the requirement for the development of progressive control methods that would meet the needs of a given converter. In response to this requirement many control methods have been developed, showing different advantages and disadvantages [1-2].

A DC-DC converter may be considered as a highly nonlinear time-invariant system (VSCS) with a variable structure. Based on the theory of VSCS systems control, sliding-mode control methods have been designed which feature good dynamic properties and high stability over a wide range of loads. The main drawback of these methods is the variable switching frequency $[3,4]$. It is for this reason that sliding-mode control methods based on PWM modulation are currently being presented [5]. The progress in micro computer technologies development has brought an increase of interest in the research of advanced control methods that are more demanding in terms of computational requirements. In the digital implementation of VMC and CMC adaptive PI controllers are often applied as controllers, which are further optimized by various numerical methods or evolutionary algorithm methods [6]. In recent years there has also been intensive research into the implementation of predictive control methods in power electronics. Predictive control achieves excellent control results, however its main disadvantage lies in the necessity of knowing the accurate mathematical model of the controlled system [7-10]. There is also intensive research going on involving the implementation of artificial intelligence methods in control, especially artificial neural networks and fuzzy logic [11-21]. While fuzzy logic has found application primarily in the development of independent controllers [11-17], artificial neural networks are mostly used in interaction with other control methods and are used for adaptive filtering of signals, in the identification of system parameters, in the design of observers, as well as independent controllers [18-21].

\section{VOLTAGE MODE CONTROL}

The operation principle of voltage mode control (VMC) for a buck converter is shown in Fig. 1, where an analog version of VMC is presented.

The control strategy of the converter includes one feedback loop - the voltage feedback. As a compensator, the most commonly used type is Type 3 from Fig. 2, or the second type, if the converter is designed to work in continuous conduction mode. The voltage compensator operates to minimize the controller error, which is the difference between the actual set point voltage $U_{\text {ref }}$ and the actual value of voltage $U_{o}[2]$. 


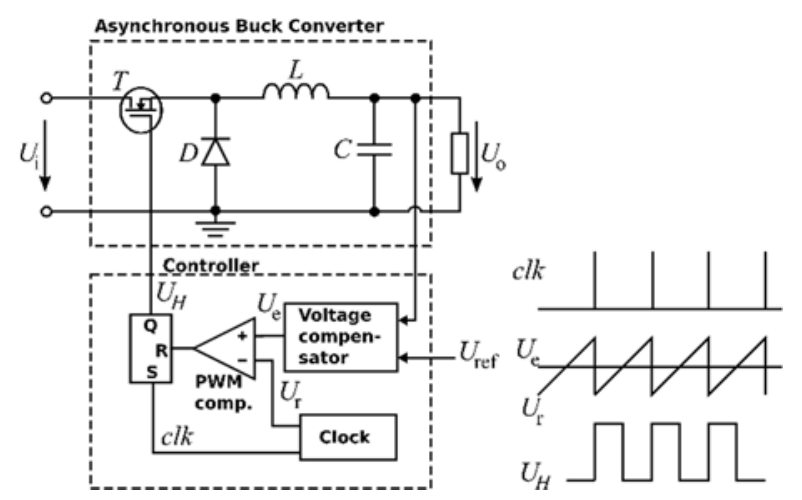

Fig. 1 VMC control of asynchronous buck converter

In order to accomplish this task, the output of controller $U_{e}$ is computed, which is used for pulse width modulation (PWM) with the generated triangle waveform [22]. Switching of the transistor gate is realized by an RS flipflop, where the output of the comparator is used to reset the output of the RS flip-flop. Opening of the transistor is achieved by setting the RS flip-flop with a clock signal, which is always generated at the end of a period of the triangle signal [23].

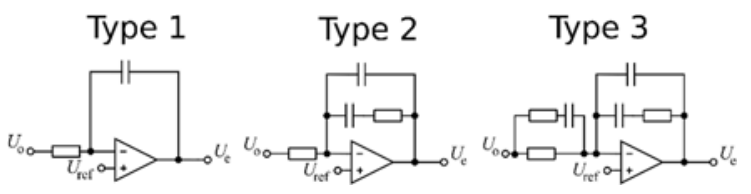

Fig. 2 Commonly used voltage compensators in dc-dc converters

The progress in microcontroller technology has brought an increasing number of applications of digital versions of VMC. Microcontrollers are generally used for implementation of such solutions (Fig. 3), with integrated modules for PWM generation, analog-digital converters and many other modules. The desired output voltage of the converter can be set to a constant value directly in the program of a microcontroller, or can be adjusted to a different set-point by a potentiometer connected to an analog-to-digital pin, or information about the desired setpoint can be sent by a variety of communication interfaces, such as I2C, SPI, CAN, etc., [24].

The main advantages of the digital version of VMC over analog can be summarized as follows [24]:

- increased accuracy, as there are no analog circuits used that could change the converter parameters due to the ageing or due to external environmental influences such as temperature, etc.

- communication with other devices

- possibility of implementation of advanced control algorithms for adaptation of the compensator (controller) to the present state of the converter

- reduced component count

On the other hand, the disadvantages of the digital version of VMC as compared to the analog version include [24]:

- limitation of maximum switching frequency of the converter depending on the clock frequency of the microcontroller

- $\quad$ higher price
- slower response to short-circuit of the converter output

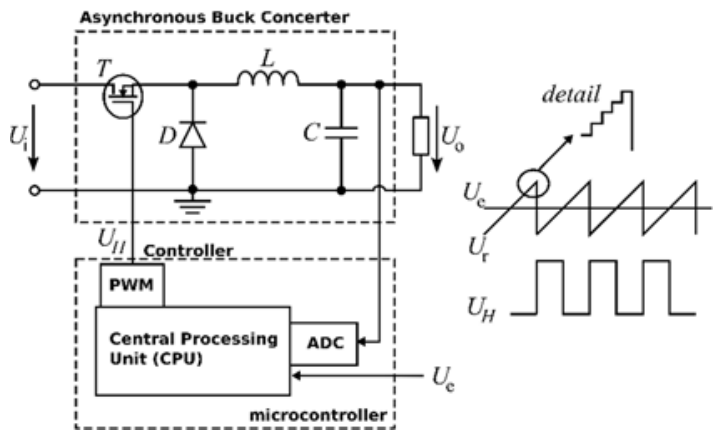

Fig. 3 Digital version of VMC

\section{CURRENT MODE CONTROL}

Current mode control (CMC) was designed with the aim of reducing the drawbacks of VMC in DC-DC power converters. As can be seen in Fig. 4, the control structure of $\mathrm{CMC}$ is similar to VMC.

The main difference of CMC compared to the VMC method is that the oscillator is only used to generate a clock signal of fixed frequency. The triangular signal for generating the PWM signal is replaced by a signal derived from the current flowing through the inductor of the converter. As voltage compensators, the second or third type of controllers in Fig. 4 are usually used [23].

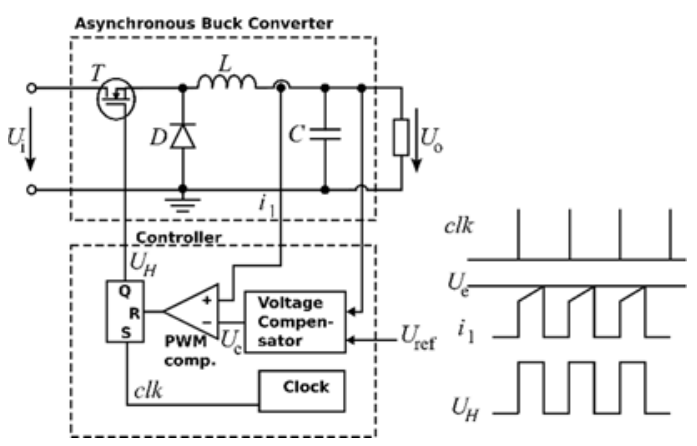

Fig. 4 CMC control of asynchronous buck converter

The CMC method typically includes current and voltage feedback. The operating principle of the $\mathrm{CMC}$ method is shown in Fig. 4. Based on the measured voltages on the load and set-point voltage the error of the voltage loop is determined. The error is calculated and processed in a voltage compensator whose output voltage $U_{e}$ is compared with the current flowing through the inductor (voltage output of current sensor), which determines the duty cycle of the switching controller. The CMC method can be implemented on a microcontroller, similarly to VMC [6].

\section{HYSTERETIC CONTROL}

Hysteretic control (HC) works on the principle of keeping the output voltage within a defined hysteresis band around the value of the desired set-point converter voltage $U_{r e f}$. This control method features a rather quick response 
to the input voltage and output voltage of the converter, since it does not contain the slow feedback found in other methods, and there are no restrictions regarding the configuration. The duty cycle can be changed in the full range from 0 to 1 . The dynamic control properties enable a size reduction of output filters, resulting in reduced total costs of the DC-DC converters [1, 6, 23, 25]. A schematic representation using $\mathrm{HC}$ for a direct step down converter is shown in Fig. 5.

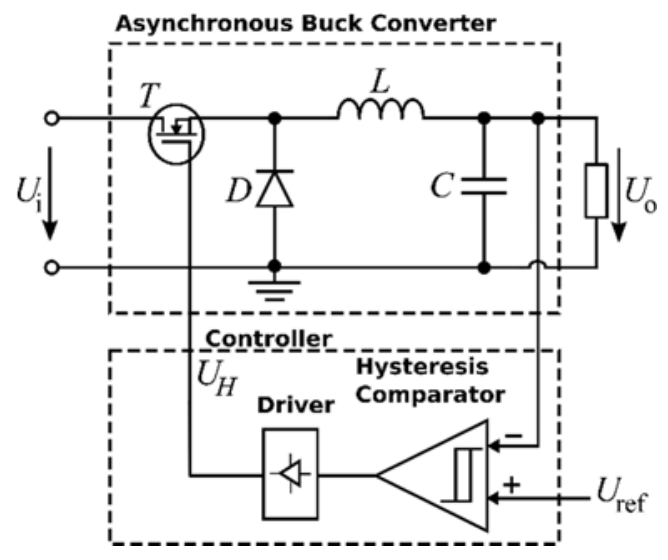

Fig. 5 Hysteretic control of asynchronous buck converter

The ripple of output voltage depends on the size of the hysteresis range and overshoot, which is caused by signal delays and the structure of the converter. Fig. 6 shows the hysteresis range (from $U_{L}$ to $U_{H}$ ) and the total output voltage ripple (from $U_{\min }$ to $U_{\max }$ ).

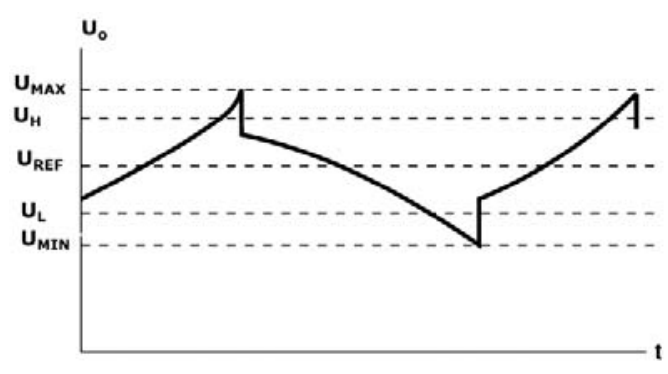

Fig. 6 Voltage ripple of HC control

\section{SLIDING MODE CONTROL}

Sliding mode (SM) control is a nonlinear control strategy, which was introduced to control variable structure systems. The most significant advantages of this control strategy are guaranteed stability, easy implementation compared to other non-linear controllers, and robustness as opposed to variations and uncertainties. Due to the benefits listed above, this control strategy is often considered and implemented in DC-DC converters mainly in the research area [3].

SM control works on the principle of employing a certain sliding surface as the reference path, so that the controlled state variable can be directed towards the desired equilibrium. The main idea of this control strategy is the application of particular rules to achieve the desired switching of transistors so that the state variables trajectory can reach the desired equilibrium along the reference path. State variables of the DC-DC converter or variables derived from the state variables, such as control error or its derivation, are usually selected as variables for slide control design. The principle of sliding mode control is shown in Fig. 7, where $X_{1}$ and $X_{2}$ represent state variables [4, 5].

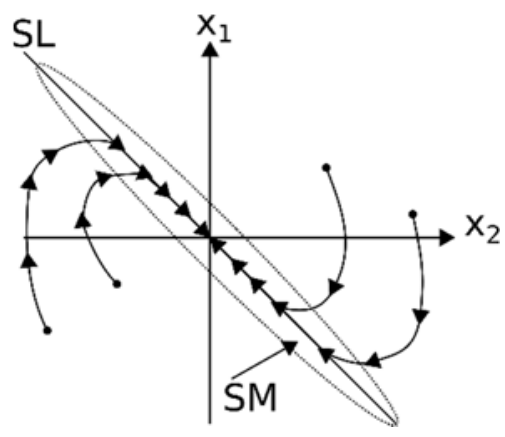

Fig. 7 The principle of SMC

In order to achieve ideal sliding mode control we need infinite switching frequency, which is not feasible in realworld applications. So often a hysteresis zone is defined around the sliding line, whereby we can limit the switching frequency directly according to the size of the hysteresis zone. This principle is shown in Fig 8, where the sliding surface is defined in the regulation error $e$ and its derivation $d_{e u}$.

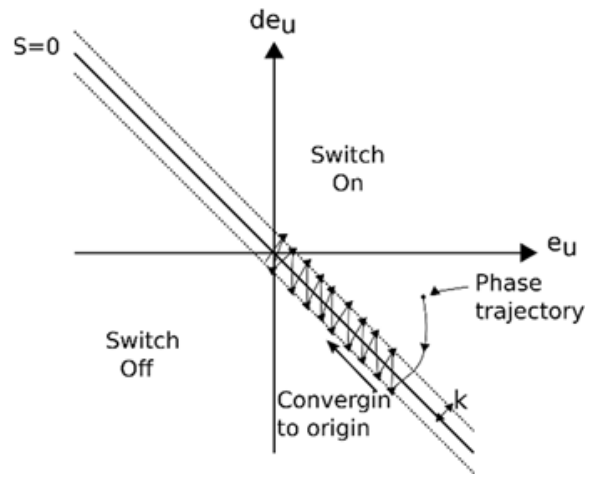

Fig. 8 The principle SMC with hysteresis

One of the major drawbacks of SMC is often considered to be the variable switching frequency during load variations, which is unacceptable in certain applications. To overcome this drawback, sliding mode control strategies with fixed frequency using PWM have been proposed [26].

\section{PID CONTROL}

Proportional-integral-derivative (PID) control is the most commonly applied type of control and it is estimated that about $90 \%$ of industrial applications use a PID controller due to its simple implementation, simple and fast calculation, easily comprehensible operating principle, as well as higher efficiency and quality of control [6, 27]. PID controllers are also often used in DC-DC converters as compensators in VMC and CMC and present one of the most widespread methods of regulation, for which reason most of the other control methods are compared to PID control. Detailed descriptions of PID control theory and its applications can be found in various sources [27]. In practical applications a simplified PI controller is often used (the derivative gain controller is omitted because of its high sensitivity to interference) [13]. For optimal 
adjustment, proportional and integral parts of the controller are often used with adaptive PI controllers [6], where proportional and integral parts are adjusted in order to achieve the best possible quality of control.

\section{ARTIFICIAL NEURAL NETWORK}

There has been increasing interest in the application of artificial neural networks (ANNs) in the development of control systems [18]. ANNs are commonly used for processing and filtering signals, for estimating and predicting signals [28], or as stand-alone controllers [30]. The operation principle of neural networks is derived from biological neural systems, such as the human brain. Some of the most significant features of an ANN are its learning ability, adaptation and generalization. Although computational and memory demands have precluded a wider application of ANNs, recent advancements in embedded systems development have opened wider opportunities for using ANNs in systems with fast dynamics. In recent years, ANNs were under consideration in many advanced control techniques in the field of electric drives [28], and currently there is increasing research into the implementation of ANNs in power electronics.

In [29] an ANN is applied to identify the load of a DC$\mathrm{AC}$ converter. The load value is further used in a deadbeat controller that determines an "ideal" control action. The use of an ANN for adjustment of the PID gains of a controller for an asymmetric direct buck converter is analyzed in [20]. The solution achieved a faster stabilization of output voltage at load change of the converter and reduced total overshoot to improve the transition response of the converter. There are also applications where ANN is used as an independent controller of a converter [21].

\section{FUZZY LOGIC CONTROL}

Fuzzy logic provides a methodology for representation, processing and implementation of human knowledge and its application in the control of dynamic systems. Fuzzy logic is most commonly used in standalone controllers, i.e. fuzzy logic controllers, which replace traditional PID controllers, or for adaptation gains of PID controllers. In contrast with conventional control methods, the main advantage of the FLC is that it is not necessary to know the exact mathematical model of a system. Instead of mathematical models, linguistic information about the system is used and its control is transferred into mathematical form. In this way it is possible to achieve robustness of the controlled systems. The relevance of fuzzy logic in control has been verified in many industrial applications and it is generally used in the control of nonlinear systems and systems where it is difficult to determine the parameters or where the parameters vary. Application of the FLC is also being considered in the control of various power electronics devices [11 - 15]. The main advantages of fuzzy control over a traditional PID controller are that there is no need to know the exact mathematical model of the controlled system, as well as the possibility of working with uncertain inputs. Moreover, fuzzy control is suitable for the control of nonlinear systems and is characterized by high robustness.
Fuzzy PI control is one of the most common forms of fuzzy logic applied in controllers. So far many different types of controllers based on fuzzy logic have been designed, which involved the use of various inputs and outputs, as in [12]. Fuzzy PI controllers that use regulation error $e$ and its derivative $\Delta e$ as inputs to the system can be seen in Fig. 9 [11].

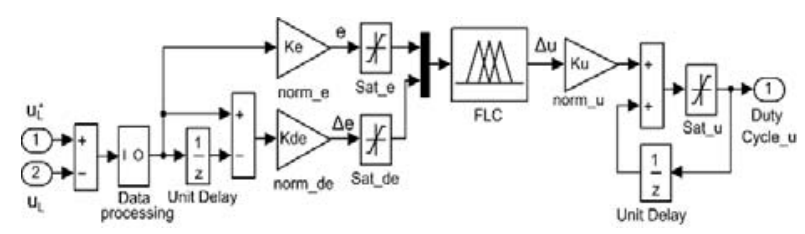

Fig. 9 Fuzzy logic controller [11]

In [13] a PID controller is compared with a fuzzy PID controller for a buck and boost converter. Experimental results have shown that both types of controllers are stable in steady state. The FLC controller had a better transition response because of achieving a smaller overshoot during load changes. In other experiments both controllers achieved similar results.

\section{CONCLUSIONS}

This paper presents a review of standard control strategies for DC-DC converters, the functionality of which has been confirmed by practical implementation in industry, and of advanced control strategies currently being developed to eliminate the drawbacks of standard control strategies, or to improve the transient response of converters. The paper shortly describes the basics of the particular control strategies and the individual advantages and disadvantages of each presented method. It can be concluded that the choice of the optimal control technique depends on the requirements of the particular converter and that there is still space for developing more efficient and more reliable control strategies.

\section{ACKNOWLEDGMENTS}

This publication is the result of the Project implementation: University Science Park TECHNICOM for Innovation Applications Supported by Knowledge Technology - II. phase, ITMS: 313011D232, supported by the Research \& Development Operational Programme funded by the ERDF. We support research activities in Slovakia/This project is being co-financed by the European Union

\section{REFERENCES}

[1] VERMA, S. - SINGH S. K. - RAO, A. G.: Overview of control Techniques for DC-DC converters, Journal of Engineering Research, Vol. 2, No. 8, pp. 18-21, 2013.

[2] LEŠO M. - ŽILKOVÁ, J. - PÁSTOR M.: Control Methods of DC-DC converters, Elektrotechnické listy, Vol. 1, No. 1, str. pp., 2016.

[3] GULDEMIR H.: Study of Sliding Mode Control of DC-DC Buck Converter, Energy and Power Engineering, Ročník 3, Číslo 4, str. 401-406, 2011. 
[4] SHAHIDA L. R. - GEORGE T. M.: Implementation of sliding mode control for a buck converter in a photovoltaic system, International Conference in Advances in Green Energy (ICAGE), pp. 245-250, 2014.

[5] BISWAL M.: Control techniques for DC-DC buck converter with improved performance, Diploma thesis, National Institute of Technology Rourkela, 2011.

[6] TAEED F. - ANDERSEN K. H. - NYMAND M.: Adaptive digital current mode controller for DC-DC converters, 17th European Conference Power Electronics and Applications, pp. 1-9, Geneva, 2015.

[7] PÁSTOR M.: DC/AC meniče pre obnovitel'né zdroje, dizertačná práca, Technická Univerzita v Košiciach, Fakulta elektrotechniky a informatiky, pp. 189, 2014.

[8] VAZQUEZ S. - LEON J.I - FRANQUELO L. G. RODRIGUEZ J., YOUNG H. A. - MARQUEZ A. ZANCHETTA P.: Model Predictive Control: A Review of Its Applications", Power Electronics, in Industrial Electronics Magazine, Vol. 8, No. 1, pp. 16-31, 2014.

[9] LIU K. Z. - YOKOZAWA Y.: An MPC-PI approach for buck DC-DC converters and its implementation, IEEE International Symposium Industrial Electronics (ISIE), pp. 171-176, 2012.

[10] ABEDI M. - BYEONG-MUN S. - RAE-YOUNG K.: Nonlinear-model predictive control based bidirectional converter for V2G battery charger applications, IEEE Vehicle Power and Propulsion Conference (VPPC) 2011, pp.1-6, 2011.

[11] LEŠO M. - ŽILKOVÁ J. - PÁSTOR M. - DUDRIK J.: Fuzzy Logic Control of Soft-Switching DC-DC Converter, Elektronika ir Elektrotechnika, Vol. 22, No. 5, pp. 3-7, 2016.

[12] LOUZAZNI M. - AROUDAM E.: Control and stabilization of three-phase grid connected photovoltaics using PID-Fuzzy logic, in IEEE International Conference on Intelligent Energy and Power Systems (IEPS), pp. 279-284, 2014.

[13] LIPING G. - HUNG J.Y. - NELMS R.M.: Evaluation of DSP-Based PID and Fuzzy Controllers for DC-DC Converters, IEEE Transactions on Industrial Electronics, Vol. 56, No. 6, pp. 2237-2248, June 2009.

[14] MANN G. K. I. - BAO-GANG HU - GOSINE R.G.: Analysis of direct action fuzzy PID controller structures, IEEE Transactions on in Systems, Man, and Cybernetics, Part B: Cybernetics, Vol. 29, No. 3, pp. 371-388, 1999.

[15] NGUYEN GIA MINH THAO - MAI TUAN DAT TRAN CONG BINH - NGUYEN HUU PHUC: PIDfuzzy logic hybrid controller for grid-connected photovoltaic inverters, International Forum on Strategic Technology (IFOST), pp.140-144, 13-15 Oct. 2010.
[16] JAWHAR S. J. - MARIMUTHU N. S. - SINGH N. A.: A Neuro-Fuzzy Controller for a Non Linear Power Electronic Boost Converter, 3rd International Conference on Information and Automation, pp. 394397, 2006.

[17] NETTARI Y. - HARMAS M. N.: Genetic algorithm based adaptive fuzzy terminal synergetic DC-DC converter control, in Control, Engineering \& Information Technology (CEIT), pp. 1-7, 2015.

[18] BOSE B. K.: Neural Network Applications in Power Electronics and Motor Drives-An Introduction and Perspective, IEEE Transactions on Industrial Electronics, Vol. 54, No. 1, pp. 14-33, 2007.

[19] MOHAMED Y. A. R. - EL-SAADANY E. F.: Adaptive Discrete-Time Grid-Voltage Sensorless Interfacing Scheme for Grid-Connected DG-Inverters Based on Neural-Network Identification and Deadbeat Current Regulation, IEEE Transactions on Power Electronics, Vol. 23, No. 1, pp. 308-321, 2008.

[20] MARUTA H. - MOTOMURA M. - KUROKAWA F.: An Evaluation Study on Circuit Parameter Conditions of Neural Network Controlled DC-DC Converter, International Conference on Machine Learning and Applications (ICMLA), Vol. 2, No. 249254, 2013.

[21] JITEURTRAGOOL N. -WANNABOON C. - SANUM W.: A power control system in DC-DC boost converter integrated with photovoltaic arrays using optimized back propagation Artificial Neural Network, 5th International Conference on Knowledge and Smart Technology (KST), pp. 107-112, Thailand, 2013.

[22] JIAN SUN: Dynamics and Control of Switched Electronic Systems, Chapter 2 - Pulse-Width Modulation, ISBN: 978-1-4471-2884-7, 2012.

[23] MANIKTALA S.: Voltage-Mode, Current-Mode (and Hysteretic Control), Technical note, 2012.

[24] BALOGH L.: A Practical Introduction to Digital Power Supply Control, Texas Instruments Incorporated, 2005.

[25] SCHROM G. - ET AL.: A 480-MHz, multi-phase interleaved buck DC-DC converter with hysteretic control, Power Electronics Specialists Conference, pp. 4702-4707, 2004.

[26] HUSSAINY S. A. A. - TANDON R. G. - KUMAR S.: PWM Based Sliding Mode Control of DC-DC converters, International Conference on Advances in Power Conversion and Energy Technologies, pp. 1-6, Mylavaram, Andhra Pradesh, 2012.

[27] KIAM HEONG ANG - CHONG G. - YUN LI: PID control system analysis, design, and technology, IEEE Transactions on Control Systems Technology, Vol.13, No.4, pp. 559-576, 2005.

[28] KUROKAWA F. - MOTOMURA M. - UENO K. MARUTA H.: A new neural network predictor for 
digital control DC-DC converter, IEEE Vehicle Power and Propulsion Conference, pp. 643-646, Seoul, 2012.

[29] MOHAMED Y. A. R. - EL-SAADANY E. F.: Adaptive Discrete-Time Grid-Voltage Sensorless Interfacing Scheme for Grid-Connected DG-Inverters Based on Neural-Network Identification and Deadbeat Current Regulation, IEEE Transactions on Power Electronics, Vol. 23, No. 1, pp. 308-321, 2008.

[30] NIZAMI T. K. - MAHANTA C.: Adaptive backstepping control for DC-DC buck converters using Chebyshev neural network, Annual IEEE India Conference (INDICON), Pune, pp. 1-5, 2014.

Received March 5, 2018, accepted July 11, 2018

\section{BIOGRAPHIES}

Martin Lešo (Ing.) was born in Poprad (Slovakia) in 1990. He graduated from the Department of Electrical Engineering and Mechatronics at FEI TU of Košice. He now works on getting his $\mathrm{PhD}$ at the same department at FEI TU of Košice. His research interests include robotics, artificial intelligence, power electronics and electrical drives.

Jaroslava Žilková (Doc., Ing., PhD.) received the MSc. Degree at the Technical University of Košice, at the Department of Technical Cybernetics of the FEI. She finished her $\mathrm{PhD}$.
Thesis, which dealt with estimation of induction motor variables based on artificial neural networks, in 2001 at the Department of Electrical Drives of the Faculty of Electrical Engineering and informatics at the same university. Since 2008 she has been an associative professor at the Department of electrical Drives of the FEI TU Košice. Her research interest include artificial intelligence, robotics and modern control methods of el. drives.

Milan Biroš (Ing.) was born in 1991, in Giraltovce, Slovakia. He recieved the M.Sc. degree from the Technical University of Košice, Košice, Slovakia, in 2014. He is currently pursuing the Ph.D. degree with the Department of Electrical Engineering and Mechatronics, Technical University of Košice. His dissertation thesis is aimed on multiport converters and their usage in vehicles. His research interests include electrical engineering in automotive applications, mechatronics, green transportation, and control of multisource electric microgrids.

Peter Talian studied at the Technical University in Košice, where he obtained his degree in Electrical Engineering degree program in 2014. Currently, he is a student of doctoral study in the study program Electrotechnical Systems. In his work he deals with hardware-in the loop in the field of control of electric drives and mechatronic systems. In 2015, he attended the Scientific Conference SCYR 2015, where he ranked first in the EEE - Electrical and Electronics Engineering category in the 1st Year of the 15th Student Conference of the Scientific Conference of Young Researchers 2015. 